Original Research Article

\title{
Comparison of $0.5 \%$ Bupivacaine and $0.5 \%$ Ropivacaine epidurally in lower limb orthopaedic surgeries
}

\author{
Ushma D. Shah*, Krunal N. Dudhwala, Mukesh S. Vakil
}

Department of Anaesthesiology, Sal Hospital and Medical Institute, Ahmedabad, Gujarat, India

Received: 04 January 2017 Accepted: 09 January 2017

*Correspondence to:

Dr. Ushma D. Shah,

Email:

ushmakhushi@gmail.com

Copyright: (C) the author(s), publisher and licensee Medip Academy. This is an openaccess article distributed under the terms of the Creative Commons Attribution NonCommercial License, which permits unrestricted noncommercial use, distribution, and reproduction in any medium, provided the original work is properly cited.

\begin{abstract}
Background: Ropivacaine in equi-potent concentrations with bupivacaine, the degree of motor blockade is less pronounced with ropivacaine, and there is a greater propensity for blocking pain transmitting A-delta and $\mathrm{C}$ fibres rather than A- $\alpha$ motor fibres. It appears to have most of the blocking characteristics of bupivacaine. So we have undertaken the study to compare ropivacaine $0.5 \%$ $(20 \mathrm{ml})$ and bupivacaine $0.5 \%(20 \mathrm{ml})$ for epidural anaesthesia in patients undergoing lower limb orthopaedic surgeries.
\end{abstract}

Methods: This double-blind, randomized study involves 60 patients who were undergone orthopaedic surgery, having ASA-I or ASA-II physical status. Out of 60,30 patients received $20 \mathrm{ml}$ of $0.5 \%$ ropivacaine and 30 patients received 20 $\mathrm{ml}$ of $0.5 \%$ bupivacaine at the L3, 4 interspace. Parameters measured were the onset time, duration and spread of sensory block, the onset time, peak time, duration and degree of motor block, the quality of anaesthesia and the heart rate and blood pressure profile during block onset.

Results: Epidurally, Ropivacaine in comparison to Bupivacaine provides quicker onset, early peak effect and prolonged duration of sensory block and shorter duration of motor block. Ropivacaine provides prolonged effective analgesia. It reduces requirement of rescue analgesics and related side effects. Conclusions: Ropivacaine $0.5 \%$ is safer and effective alternative to Bupivacaine in epidural anaesthesia and post operative pain relief.

Keywords: Bupivacaine, Epidural, Lower abdominal surgery, Ropivacaine

\section{INTRODUCTION}

The recognition of acute life-threatening cardiotoxicity of bupivacaine lead to the search for a local anaesthetic agent comparable with bupivacaine but with lower cardiotoxicity resulting in development of a relatively new amide, ropivacaine. Ropivacaine is produced as pure ' $\mathrm{S}$ ' enantiomer with lower lipid solubility, easier reversibility after inadvertent intravascular injection, significant reduction in central nervous system toxicity, lesser motor block and greater differentiation of sensory and motor block. ${ }^{1,2,3}$ In equi-potent concentrations the degree of motor blockade is less pronounced with ropivacaine, and there is a greater propensity for blocking pain transmitting A-delta and $\mathrm{C}$ fibres rather than $\mathrm{A}-\alpha$ motor fibres. Ropivacaine has enormous potential as a local anaesthetic agent. ${ }^{4,5}$ It appears to have most of the blocking characteristics of bupivacaine. These findings created interest to study this new anaesthetic agent for block characteristics and safety profile and to compare this drug with commonly used drug bupivacaine and to know whether it can replace this older anaesthetic agent in future. So we have undertaken the study to compare ropivacaine $0.5 \%(20 \mathrm{ml})$ and bupivacaine $0.5 \%(20 \mathrm{ml})$ for epidural anaesthesia in patients undergoing lower limb orthopaedic surgeries.

\section{METHODS}

A randomized prospective clinical study of patients undergoing elective lower limb orthopaedic surgeries receiving either epidural ropivacaine or bupivacaine was undertaken after obtaining written informed consent and institutional approval. Sixty patients divided into two groups of 30 each by computer generated random number, Group $\mathrm{R}$ to receive $20 \mathrm{ml}$ of $0.5 \%$ ropivacaine 
and Group B to receive $20 \mathrm{ml}$ of $0.5 \%$ bupivacaine. We included adult patients aged between 18 and 65 years of both sexes of American Society of Anaesthesiologists (ASA) physical status Grade I and II for the study. Exclusion criteria included known allergy to local anaesthetics, local infections, coagulopathy, and patients on antiarrhythmic treatment. All patients were matched for Indian height and weight. After pre anaesthestic checkup, patients were kept fasting from previous night and premedicated with Inj. Atropine $0.6 \mathrm{mg}$ iv and Inj. Ranitidine $50 \mathrm{mg}$ iv were given and preloading was done with Inj. Ringer Lactate $10 \mathrm{ml} / \mathrm{kg}$ body weight 20 minutes prior to induction. All epidural blocks were performed under strict aseptic precautions in sitting position and 18 $\mathrm{G}$ epidural needle was inserted in L3-4 interspace (midline approach) and epidural catheter was introduced. After $3 \mathrm{~min}$ of test dose of $2 \mathrm{ml} 2 \%$ lignocaine with adrenaline 1:200,000, in absence of signs of subarachnoid and intravascular injection, $20 \mathrm{ml}$ of test drug was administered over $2 \mathrm{~min}$ in increments, after negative aspiration for blood and cerebrospinal fluid. Time of completion of injection of drug was recorded as $0 \mathrm{~min}$. In both the groups, bilateral blockade assessments were performed repeatedly at $1,3,5,10,15 ; 30$ min then after every 30 min till surgery is over. Onset of sensory block measured as time interval from injection of drug epidurally to dull sensation on pin prick with 24G hypodermic needle at L1 Dermatome. Peak of blockade measured as Loss of sensation to pin prick (with $24 \mathrm{G}$ hypodermic needle) at L1 Dermatome, Highest level of sensory block to be achieved is T10 and time to achieve the same were noted. Duration measured as Time interval between onsets of sensory block to regression of segmental sensory block to L1 dermatome again. Two segment regression of the sensory blockade from the maximum sensory segmental level (T10) as well as total duration of sensory blockade was noted too. Motor block estimated at these same intervals using the BROMAGE scale. Onset of motor block, Maximum motor block achieved, Time to achieve maximum motor block and Duration of motor block were noted. All the patients were given Inj. Midazolam 0.01-0.02 $\mathrm{mg} / \mathrm{kg}$ intravenous as sedation. All the patients were monitored for vital parameters, sensory and motor blockade and complications if any. Vital parameters were monitored using multipara monitor. Pulse Rate, Systolic Blood Pressure, Diastolic Blood Pressure, Oxygen saturation were recorded at $0,1,3,5,10,15,30 \mathrm{~min}$ and there after every 30 mins till the end of the surgery. All the patients were monitored for any intraoperative complications like - Hypotension, Bradycardia, Nausea / vomiting. Top up dose of $5 \mathrm{ml}$ of group drug was given if sensory level regresses to L1 and time for the same was noted. Duration of surgery (In hours), total amount of blood loss and fluid replaced were noted. Epidural catheter was removed at the end of the surgery. The patients were monitored post operatively for vital parameters, analgesia and any complication every hourly till $8 \mathrm{hrs}$ and thereafter 6 hourly till 24 hours. Pain was noted in the both the groups using visual analogue scale (VAS). A linear visual analogue scale of $10 \mathrm{~cm}$ was used graded from 0-10 that is from no pain to worst pain. The patient was asked to mark the point on the scale that corresponds to his/her intensity of pain. The duration of effective analgesia was counted from epidural administration of drug to first dose of rescue analgesia. Rescue analgesia (RA) in form of Inj. Diclofenac $1.5 \mathrm{mg} / \mathrm{kg}$ intra muscular was administered when the VAS was more than and equal to 4 . Inj. Diclofenac $1.5 \mathrm{mg} / \mathrm{kg}$ IM was repeated if the patient complained of pain in next 24 hours. Total no. of analgesics required in first 24 hours was noted. The patients were observed for the complications. The results of the study were tabulated and statistically analyzed using Student's t test and Chi square test after calculating mean and Standard Deviation (SD) for the individual group and the inter and intra group comparison. The $\mathrm{P}$ value $<0.05$ considered significant and $P$ value $<0.001$ highly significant.

\section{RESULTS}

Demographic data in terms of age, sex, ASA physical status, mean duration of surgery, types of surgeries were comparable in both the groups. The mean time for onset of sensory block was $106.33 \pm 13.51 \mathrm{sec}$ in Group R and $168.66 \pm 17.75 \mathrm{sec}$ in Group B. The mean time for peak effect of sensory block was $3.56 \pm 0.63 \mathrm{~min}$ in Group $\mathrm{R}$ and 7.66 $\pm 0.84 \mathrm{~min}$ in Group B. The mean time to achieve highest level sensory block was 7.56 \pm 1.07 min in Group $\mathrm{R}$ and $11.73 \pm 1.04$ min in Group B which was achieved faster in Group R than in Group B. Thus the onset, peak effect and duration of sensory blockade were faster in Group $\mathrm{R}$ than in Group B. The mean duration of sensory block was $257.66 \pm 14.78 \mathrm{~min}$ in Group $\mathrm{R}$ and $222 \pm 20.24$ min in Group B, the difference being statistically highly significant $(\mathrm{P}<0.001)$. In both the groups, maximum height of segmental sensory block achieved was T10 in most of the patients (28 in Group R and 29 in Group B) which is comparable. The mean time for onset of motor block was $525 \pm 50.29$ seconds in Group R and 505 \pm 56.31 seconds in Group B. The mean time for peak effect of motor block was $26.83 \pm 2.07 \mathrm{~min}$ in Group $\mathrm{R}$ and $25.93 \pm 1.76 \mathrm{~min}$ in Group B. The mean duration of motor block was $202 \pm 17.49 \mathrm{~min}$ in Group R and 260 $\pm 18.19 \mathrm{~min}$ in Group B. Thus in Group $\mathrm{R}$ the onset, peak effect and duration of sensory block was faster compared to Group B. Duration of motor block was shorter in group $\mathrm{R}$ in comparison to Group B. Surgical anaesthesia was adequate in all the cases and there was not a single failure case in either of the two groups. None of the patients in both the groups required epidural top up dose. The intragroup and inter-group comparison did not show any significant change in mean pulse rate, systolic and diastolic $\mathrm{BP}$ and $\mathrm{SpO}_{2}$ throughout the study when compared with pre-operative values. The duration of effective analgesia was counted from epidural administration of drug to when VAS score of 4 or more. Postoperatively, the mean VAS score was lower in group $\mathrm{R}(0,0.93,1.7,2.17,2.87,3.47,3.93,4$ at $1,2,3,4,5,6,7,8$ hours) than in group B $(0.13,1.07,2.0,2.53,3.47,4$ at 1,2 , 
3, 4, 5, 6, 7,8hours) respectively. On inter-group comparison, there showed statically significant difference in mean VAS score at 2, 3, 4 ( $\mathrm{p}<0.05)$ and highly significant at 5, 6 hours $(\mathrm{P}<0.001)$. At the end of 3 hours none of the patients required rescue analgesics in both the groups (VAS score $2.0 \pm 0.49$ in group B Vs $1.7 \pm 0.45$ in group R). At the end of 4 hours, mean VAS score was $2.17 \pm 0.38$ but none of patients were given rescue analgesia in Group $\mathrm{R}$ while it was $2.53 \pm 0.57$ and 01 $(03.33 \%)$ patient was given rescue analgesia in Group B. At the end of 5 hours, mean VAS score was $2.87 \pm 0.56$ and $03(10 \%)$ patients were given rescue analgesia in Group R while it was $3.47 \pm 0.51$ and $14(46.67 \%)$ patients were given rescue analgesia in Group B. At the end of 6 hours, mean VAS score was 3.47 \pm 0.51 and 14 (46.67\%) patients were given rescue analgesia while it was 4 in Group B and, remaining patients $(100 \%)$ were given rescue analgesia At the end of 8 hours, mean VAS score was achieved 4 Group $\mathrm{R}$ and remaining patients (100\%) were given rescue analgesia. The mean duration of analgesia was $375 \pm 45.77 \mathrm{~min}$ in Group $\mathrm{R}$ as compared to $312 \pm 35.76 \mathrm{~min}$ in Group B, thus it was prolonged in Group R, the difference being statistically highly significant. Also the analgesic requirement in $24 \mathrm{hr}$ post operative period was less; $2.17 \pm 0.46$ in Group $\mathrm{R}$ as compared to $2.7 \pm 0.53$ in Group B with $20 \%$ reduction in diclofenac requirement in Group $R$. There were no postoperative sequelae like headache, backache, nausea and vomiting for next $24 \mathrm{~h}$.

\section{DISCUSSION}

Epidural anaesthesia reduces perioperative physiologic responses in addition to providing pain relief. Ropivacaine was identified in 1957, but not evaluated fully until 1988 after the alarming editorial by Albright observing difficult resuscitation and poor outcome after accidental intravascular injection of bupivacaine. ${ }^{7}$ In the present study, in patients who received ropivacaine the mean onset time of sensory block was faster than in those who received bupivacaine. The onset, peak effect and duration of sensory blockade were faster in Group $\mathrm{R}$ than in Group B. In a similar study, Finucane et al. ${ }^{8}$ found that onset time for sensory block to T12 was shorter in $0.5 \%$ ropivacaine group when compared to $0.5 \%$ bupivacaine group. The mean time for onset and peak effect of motor block was early in Group B. Duration of motor block was shorter in group R in comparison to Group B. Brockway et al. ${ }^{9}$ showed that motor block produced by ropivacaine was slower in onset. Time for two segment regression of sensory block in both groups was comparable. Concepcion et al. ${ }^{5}$ found a mean time for two segment regression as $164 \pm 22 \mathrm{~min}$ for ropivacaine, which was comparable to present study. The mean duration of analgesia was $375 \pm 45.77 \mathrm{~min}$ in Group $\mathrm{R}$ as compared to $312 \pm 35.76$ min in Group B, thus it was prolonged in Group $R$, the difference being statistically highly significant. The mean time for complete motor recovery in present study was comparable in both groups. Brown et al and Cekmen et al showed that duration of motor block was significantly longer in the $0.5 \%$ bupivacaine group as compared to $0.5 \%$ ropivacaine. Zaric et al found that motor blockade with $0.75 \%$ ropivacaine was comparable to $0.5 \%$ bupivacaine. ${ }^{4,6,10}$ There were no significant changes in mean pulse rate and mean arterial pressure between two groups in present study, findings shared by other studies. ${ }^{4,5}$ There were no postoperative sequelae like headache, backache, nausea and vomiting for next $24 \mathrm{~h}$ which is in consonance with Brown et al. ${ }^{4}$

\section{CONCLUSION}

Epidurally, Ropivacaine in comparison to Bupivacaine provides quicker onset, early peak effect and prolonged duration of sensory block and shorter duration of motor block, prolonged effective analgesia. It reduces requirement of rescue analgesics and related side effects. It provides stable hemodynamics. Thus, Ropivacaine $0.5 \%$ is safer and effective alternative to Bupivacaine in epidural anaesthesia and post operative pain relief.

\section{Funding: No funding sources}

Conflict of interest: None declared

Ethical approval: The study was approved by the Institutional Ethics Committee

\section{REFERENCES}

1. Whiteside JB, Wildsmith JA. Developments in local anaesthetic drugs. Br J Anaesth. 2001;87:27-35.

2. Leone S, Di Cianni S, Casati A, Fanelli G. Pharmacology, toxicology, and clinical use of new long acting local anesthetics, ropivacaine and levobupivacaine. Acta Biomed. 2008;79:92-105.

3. Stienstra R. The place of ropivacaine in anesthesia. Acta Anaesthesiol Belg. 2003;54:141-8.

4. Brown DL, Carpenter RL, Thompson GE. Comparison of $0.5 \%$ ropivacaine and $0.5 \%$ bupivacaine for epidural anesthesia in patients undergoing lower-extremity surgery. Anesthesiology. 1990;72:633-6.

5. Concepcion M, Arthur GR, Steele SM, Bader AM, Covino BG. A new local anesthetic, ropivacaine. Its epidural effects in humans. Anesth Analg. 1990;70:80-5.

6. Zaric D, Axelsson K, Nydahl PA, Philipsson L, Larsson P, Jansson JR. Sensory and motor blockade during epidural analgesia with $1 \%, 0.75 \%$, and $0.5 \%$ ropivacaine- a double-blind study. Anesth Analg. 1991;72:509-15.

7. Albright GA. Cardiac arrest following regional anesthesia with etidocaine or bupivacaine. Anesthesiology. 1979;51:285-7.

8. Finucane BT, Sandler AN, McKenna J, Reid D, Milner AL, Friedlander M, et al. A double-blind comparison of ropivacaine $0.5 \%, 0.75 \%, 1.0 \%$ and bupivacaine $0.5 \%$, injected epidurally, in patients undergoing abdominal hysterectomy. Can J Anaesth. 1996;43:442-9. 
9. Brockway MS, Bannister J, McClure JH, McKeown D, Wildsmith JA. Comparison of extradural ropivacaine and bupivacaine. $\mathrm{Br} \mathrm{J}$ Anaesth. 1991;66:31-7.

10. Cekmen N, Arslan M, Musdal Y, Babacan A. Comparison of the effects of a single dose of epidural ropivacaine and bupivacaine in arthroscopic operations.Medwell Res J Med Sci. 2008;2:109-15.

Cite this article as: Shah UD, Dudhwala KN, Vakil MS. Comparison of $0.5 \%$ Bupivacaine and $0.5 \%$ Ropivacaine epidurally in lower limb orthopaedic surgeries. Int J Basic Clin Pharmacol 2017;6:271-4. 